студентов к дальнейшему его изучению, 7\% студентов экспериментальной группы продолжили изучение английского языка на дополнительных языковых программах и курсах.

На наш взгляд, применение данной модели в учебном процессе должно происходить в полном объеме. Этот процесс включает в себя: мотивацию, стимуляцию к обучению, организацию полнозавершенного цикла познавательной деятельности, что приводит к глубокому усвоению и запоминанию учебного материала, а именно это позволяет подготовить высококвалифицированных специалистов, обладающих творческим потенциалом.

$$
* * *
$$

1. Выготский Л.С. «Педагогическая психология», Умственное развитие детей в процессе обучения. М.: Педагогика, 2007г. с. 46-49

2. Городецкая Е.Я. Роговая Н.А. «Теоретические основания формирования творческих компетенций субъектов образования в условиях университетского комплекса», Некоторые психологопедагогические закономерности активизации познавательной деятельности, Владивосток 2014г. c118-137

3. Копнин П.В. «Дидактика, логика, наука». Москва 1973г. с.194-197

4. Коробий Е.Б. «Активизация учебно- познавательной деятельности студентов как педагогическая проблема». -Нов. 2012. с. 73-84

5. Смирнова А.А. «Проблемы психологии памяти». - М.: Просвещение, 1966г. с. 336-339

6. Талызина Н.Ф. «Теоретические проблемы программированного обучения». Педагогическая психология. - М.: Академия, 1998г. с.63-89

7. Шахмартова О.М. «Активные методы обучения» : учебное пособие, издание 2-ое. - Пенза, 2011г. $131 \mathrm{c}$.

8. Cassandra L. Brown, Laura E. Gibbons and Robert F. Kennison "Scholar Commons", Social activity and cognitive function over time: a coordinated analysis of four longitudinal studies., University of South Florida, 2012 p. $541-563$

\title{
Михайлова Г.И. \\ Информационные технологии в образовании: от концепции информатизации до дистанционного обучения
}

Новосибирский государственный архитектурно-строительный университет (Россия, Новосибирск)

doi: $10.18411 / l j-02-2021-150$

idsp: ljournal-02-2021-150

\section{Аннотация}

В свете современных событий, когда не только технологические прорывы, но и сама жизнь заставляет нас все интенсивнее внедрять компьютерные технологии во все сферы человеческой деятельности - от досуга до научных исследований - автор статьи предлагает взглянуть на проблему в широком ракурсе в отношении использования информационных технологий в сфере образования. Цель данной статьи не просто задать ретроспективный фокус и обозначить последние тенденции в компьютеризации образовательного процесса, но и проанализировать опыт различных этапов внедрения информационно-коммуникационных технологий. Такой подход позволяет увидеть преемственность и перспективы данного процесса.

Ключевые слова: образовательный процесс, высшие учебные заведения, информационные технологии, электронная образовательная среда, дистанционное обучение.

\section{Abstract}

In the light of modern events, when not only technological breakthroughs, but also life itself forces us to increasingly introduce computer technologies in all spheres of human 
activity - from leisure to scientific research - the author of the article suggests to look at the problem from a broad perspective in relation to the use of information technologies in education. The purpose of this article is not just to set a retrospective focus and identify the latest trends in the computerization of the educational process, but also to analyze the experience of previous stages of the introduction of information and communication technologies and evaluate them. This approach allows us to see the continuity and prospects of this process.

Keywords: educational process, higher education institutions, information technologies, electronic educational environment, distance learning.

Компьютеризация образования, также как и создание компьютерной среды в целом - это процесс, имеющий уже достаточно длительную историю. Даже если абстрагироваться от времени создания первых «умных машин», можно с уверенностью постулировать, что широкое внедрение компьютеров в повседневную жизнь человека насчитывает не один десяток лет. Интенсивность этих процессов экспоненциально нарастала на рубеже веков. Почему именно сегодня эта тема стала столь актуальной? Не секрет, что последние полтора года были отмечены возникновением сложной ситуации во всех областях жизни человека, что связано с появлением и распространением коронавирусной инфекции. Вынужденная изоляция, разрыв привычных отношений и изменение привычного образа жизни и как следствие - поиск новых решений в ответ на возникшие вызовы не оставили в стороне и сферу образования. Было ли наше образование, в частности, высшая школа, в достаточной мере готово встретить эти вызовы? Стало ли обращение к дистанционной форме обучения панацеей в решении проблем? Или, возможно, сложившиеся обстоятельства сыграли лишь роль катализатора тех инновационных процессов, которые уже нарастали внутри традиционных образовательных форм? Считаем, что эти вопросы как никогда актуальны и требуют своего рассмотрения.

Цель данной статьи - осветить тот опыт, который уже был накоплен системой образования за десятилетия внедрения технических инноваций в учебный процесс, т.е. дать своего рода ретроспекцию предыдущих этапов развития информационных технологий, а также проанализировать современные тенденции, касающиеся, прежде всего дистанционного обучения в свете ситуации полного перехода на онлайн обучение.

1. Исторический ракурс проблемы

Концепция информатизации процесса образования в Российской Федерации сформировалась в период с 1993 по 1998 год. В 90-е годы прошлого века был принят ряд документов, регулирующих этот процесс, что на концептуальном уровне стимулировало создание современной информационной среды системы высшего образования и науки. Акселерация процесса внедрения компьютерных и коммуникационных технологий была связана с присоединением к Болонскому соглашению, что охарактеризовалось началом модернизации отечественного образования в 2002 году [1].

Активизация инновационных процессов в системе образования прошлого века вызвала вполне естественные разногласия и противоречивые мнения в отношении того, каков положительный потенциал перехода отечественной образовательной системы на рельсы модернизации и что теряет образование, отходя от своих традиционных форм. Одна из статей профессора МИТХТ им. М.В. Ломоносова В. Г. Айнштейна вышла с характерным названием «Информатизация: приобретения и утраты» [2]. И если прогресс от внедрения информационных технологий в образовательный процесс не подвергался особым сомнениям, то нивелирование человеческого фактора, а в более широком смысле, этическая составляющая, вызывали явную тревогу. В.Г. Айнштейн указывал на тот факт, что никакая «умная машина» не сможет, с одной стороны, взять 
на себя столь важную в образовательном процессе воспитательную функцию, а с другой стороны, в рамках собственно получения знаний никакое техническое оснащение учебного процесса не заменит непосредственного общения преподавателя с аудиторией: «Надо понимать, что недостаток преподавательского мастерства и желания его совершенствовать нельзя восполнить никаким избытком технических средств» [2, с.89]. Нам представляется, что, не смотря на смещение акцента в новом тысячелетии в сторону большей рефлексии над технической составляющей компьютеризации и создания электронной учебной среды, человеческий фактор не должен быть сброшен со счетов.

Нужно отметить, что уже на первых этапах информатизации образования, людей, непосредственно связанных с учебным процессом, волновали вопросы, связанные с калькуляцией недостатков и преимуществ внедрения информационных и коммуникативных технологий. Преимущества виделись в ускорении и упрощении многих процессов, в быстром и неограниченном доступе к информации. Что касается недостатков, представляется важным отметить, что большинство из них в новом тысячелетии, благодаря развитию не только собственно технологий, но и проработке соответствующей методологической и дидактической базы, были преодолены. Именно в этом и заключалась суть модернизации образования - направление усилий в одновременном наращивании «эффективного использования средств информационных технологий и дидактических условий организации процесса подготовки специалистов» [3, с. 84]. Как становится понятным, инновационные тенденции в образовании, в том числе и создание информационной образовательной среды, возникли как определенная стратегия, явленная уже в конце прошлого века в рамках концепции информатизации и модернизации учебного процесса. Вполне естественно, что внедрение новых технологий непосредственно в учебную практику проходило через определенные трудности и противоречия. В XXI веке эти процессы нарастали, проблемы предыдущих этапов разрешались, возникали новые проблемы, а лучше сказать, сдвигались акценты в постановке проблем. События последних полутора лет лишь ускорили апробацию практически полного, хотя и временного перехода на дистанционное обучение.

2. Современные тенденции: дистанционное обучение

Реалии современности, связанные с пандемией, заставили пристальнее и критичнее присмотреться к идее дистанционного образования не только тех, кто напрямую связан с процессами внедрения новых технологий в учебный контекст и с осуществлением непосредственных образовательных функций, но и широкую общественность. Много критики можно услышать в отношении качества дистанционного образования. Сразу отметим, что нечеткие требования к качественному аспекту вкупе с максимально широким доступом к обучению отражает тот факт, что идея дистанционного образования соотносилась, прежде всего, с возможностью получения дополнительных образовательных возможностей наряду с непосредственным контактным обучением, либо при невозможности получения последнего. По крайней мере, именно так позиционировал себя, возникший во Франции еще в 1980 году Национальный центр дистанционного обучения, а также подобные системы в рамках проектов цифрового образования в других странах Евросоюза [4, 5]. Такого рода системы до недавнего времени не предусматривали полный переход, причем в сетке основного образовательного процесса, на дистанционный формат. Естественно, такая трансформация не могла проходить гладко. Зададимся, однако, вопросом: насколько система высшего образования справилась с ситуацией, и какую роль сыграло в этом проходившее в вузах страны в предыдущие годы внедрение электронных образовательных систем?

В 2002 году была создана электронная система управления обучением Moodle, которая стала широко использоваться в Российских вузах как универсальный портал образовательной организации. Сочетая в себе несколько классов информационных 
систем, в том числе, виртуальную среду обучения, она предоставляла большие возможности от доступа к электронной библиотечной системе до управления электронными курсами. Позже, в соответствии с нормативными образовательными документами, в вузах была создана электронная информационно-образовательная среда (ЭИОС), интегрированная с Moodle. Весьма существенным в этом контексте представляется следующее: введение на первых этапах создания информационной среды обучения асинхронных онлайн курсов (реализация посредством Moodle) дало преподавателям вузов возможность еще в «доковидные» времена научиться работать в виртуальной среде. Все преподаватели прошли повышение квалификации (и не одно!) по обучению работе с системами дистанционного обучения. Даже если судить с позиций осторожного оптимизма, нельзя отрицать тот факт, что такая подготовка вузов позволила в нужный момент с наименьшими «потерями» перейти на синхронное онлайн обучение через такие платформы как Zoom, Bigbluebutton, Microsoft Teams.

В качестве вывода хотелось бы отметить следующее: продвижение и осуществление новых технологий было и остается сложным, неоднозначным, нелинейным процессом, в ходе которого обнаруживают себя как положительные, так и отрицательные стороны. Российские вузы, оказавшись, как и вся страна, перед лицом новых сложных вызовов, в целом достойно справились с ситуацией и, что более важно, получили огромный и ценный опыт апробации работы всех систем виртуальной образовательной среды в ситуации перехода на полный онлайн режим.

$$
* * *
$$

1. Исторический обзор процесса внедрения информационных и коммуникативных технологий в образование. $\quad$ https://infourok.ru/istoricheskiy-obzor-processa-vnedreniya-informacionnih-ikommunikacionnih-tehnologiy-v-obrazovanie-1730148.html (дата обращения 01.02.2021)

2. Айнштейн В. Г. Информатизация: приобретения и утраты // Высшее образование в России. 1999. № 5. C. 89-92.

3. Езерский В., Антонов А. Компьютеризация и дидактика: поле взаимодействия // Высшее образование в России. 1999. № 5. С. 83-88.

4. Добрынин М.А., Сухой С.Н. Дистанционное образование во Франции // Дистанционное и виртуальное обучение. 2002. № 9. С. 81-85.

5. Сиволапов А.В. Компьютеризация образования: современные проблемы и перспективы развития // Образование и наука. 2005. № 2 (32). С.39-48.

\section{Муллер О.Ю. \\ Онлайн-обучение студентов с особыми образовательными потребностями}

Сургутский государственный университет (Россия, Сургут)

doi: $10.18411 / l j-02-2021-151$

idsp: ljournal-02-2021-151

\section{Аннотация}

Статья посвящена вопросам дистанционного обучения студентов с особыми образовательными потребностями путем проведения цикла онлайн-семинаров на базе интернет-платформы Moodle. Предметом анализа выступают образовательные потребности студентов с ограничениями здоровья и требования к соответствующей подготовке преподавателей. Автор ставит целью раскрыть организационные условия проведения онлайн-обучения. Методология проведения работы заключается в исследовании выбранной темы путем описания результатов наблюдения, а также интерпретации и обобщения с применением сравнительно-сопоставительного анализа. Основу исследования составили педагогическое наблюдение и сопровождение онлайнсеминаров. Результаты работы заключаются в описании автором необходимых условий организации дистанционного обучения студентов с особыми образовательными 